\title{
Repaying the Debt: An Examination of the Relationship between Perceived Organizational Support and Unethical Pro-organizational Behavior by Low Performers
}

\author{
Xiaoyu Wang ${ }^{1} \cdot$ Xiaotong (Janey) Zheng $^{2} \cdot$ Shuming Zhao ${ }^{3}$
}

Received: 17 May 2020 / Accepted: 27 March 2021 / Published online: 18 May 2021

(c) The Author(s) 2021

\begin{abstract}
Drawing on social exchange theory, we examine the conditions under which employees' good intentions motivate them to engage in unethical pro-organizational behavior (UPB) and the psychological mechanism behind this behavioral decision. Findings from a time-lagged field study and a scenario study indicate (1) an interactive effect between perceived organizational support and employee performance on UPB; (2) that low performers who perceive high levels of organizational support are more likely to engage in UPB; and (3) that feelings of indebtedness to the organization mediate the interactive effect on UPB. Therefore, the paper highlights the importance of conditional factors in motivating UPB by combining employee 'good intentions' and 'disadvantageous situations' to understand the UPB decision process. The paper concludes with theoretical and practical implications.
\end{abstract}

Keywords Unethical pro-organizational behavior · Perceived organizational support · Task performance $\cdot$ Indebtedness . Social exchange

\section{Introduction}

Although most behavioral ethics research has focused on unethical behavior by individuals (e.g., stealing, cheating and lying) that seeks to benefit their personal interests (e.g., Bersoff, 1999; Gino \& Ariely, 2012), some recent studies in the organizational context have suggested that people may engage in unethical behavior to benefit other colleagues, their work groups or the organization (Johnson \& Umphress, 2019; Thau et al., 2015; Umphress et al., 2009; Umphress, Bingham, \& Mitchell, 2010, 2019). This category

Xiaotong (Janey) Zheng

xiaotong.zheng@durham.ac.uk

Xiaoyu Wang

xiaoyuwang@tongji.edu.cn

Shuming Zhao

zhaosm@nju.edu.cn

1 Advanced Institute of Business, School of Economics and Management, Tongji University, Shanghai, China

2 Durham University Business School, Durham University, Mill Hill Lane, DH1 3LB Durham, UK

3 School of Business, Nanjing University, Nanjing, China of unethical behavior is generally defined as unethical proorganizational behavior (UPB), which refers to "actions that are intended to promote the effective functioning of the organization or its members (e.g., leaders) and violate core societal values, mores, laws, or standards of proper conduct" (Umphress \& Bingham, 2011, p. 622). Exploring antecedents and mechanisms of employee UPB can not only advance current understanding of behavioral ethics but also provide valuable practical insights into how to prevent 'good soldiers' from engaging in bad behavior in organizations.

According to Umphress and Bingham (2011), employee UPB is likely to result from a positive social exchange relationship with the organization through a process of neutralization in which employees are morally disengaged. This social exchange perspective has received empirical support in the extant studies that examine the antecedents of UPB. For instance, employees who identify highly with the organization are more likely to engage in UPB when they have higher rather than lower levels of positive reciprocity beliefs (Umphress et al., 2010). More directly, research has shown that employees engage in UPB to reciprocate their positive exchange relationships with organizations that foster high-inducement employee-organization relationships (Wang et al., 2019) or have high-performance work systems 
(Xu \& Lv, 2018). Despite these supportive empirical findings, this social exchange perspective on UPB warrants further examination as several notable ambiguities exist in the extant research.

First, the motivational mechanism underlying the relationship between positive social exchange and UPB remains under-examined. Specifically, it is unclear why employees choose to reciprocate high organization inducements by engaging in risky and negative UPB instead of making more legitimate and desirable contributions at work, such as increased work effort and task performance (Mathieu \& Zajac, 1990; Meyer \& Allen, 1997; Mowday, Porter, \& Steers, 1982). Second, social exchange is a reciprocal process between two parties (e.g., employees and their organizations). Therefore, in addition to being affected by the organization's positive social exchange practices (Wang et al., 2019; Xu \& Lv, 2018), UPB may also result from employees' own perceptions of their personal inputs and outputs in their social exchanges with the organization. For instance, Lee et al. (2019) have recently found that employees with high psychological entitlement—a belief that one deserves more inducements from the organization-are willing to take shortcuts (even in unethical ways) to make greater contributions to the organization. Therefore, it is necessary to consider resources exchanged by both the organization and the employee to gain a more complete understanding of this social exchange perspective on UPB.

The purpose of our study is to re-examine the positive social exchange perspective on UPB by developing a balanced framework that considers both organizational support and the employee's contributions as joint antecedents of UPB. Specifically, drawing on the reciprocity principle in social exchange theory (Gouldner, 1960), we theorize that high-quality employee social exchange relationships with the organization, as reflected in perceived organizational support (POS) from the employee's perspective, may not necessarily lead to UPB. Instead, we suggest that a positive relationship between POS and UPB only exists among poorly performing employees due to them feeling indebted to the organization (i.e., that they need to repay the organization; c.f. Heider, 1958)

Figure 1 depicts the conceptual model behind the study, which seeks to make several interrelated theoretical contributions to the UPB literature. First, we advance the literature by revealing a key boundary condition for positive employee-organization exchanges. Although some recent research drawing exclusively on Umphress and Bingham's (2011) seminal work has demonstrated that UPB is a negative consequence of a positive social exchange relationship with the organization (Wang et al., 2019) and the supervisor (Bryant \& Merritt, 2019), our research findings suggest that positive social exchanges may not necessarily lead to employee UPB, but only among those who receive a high

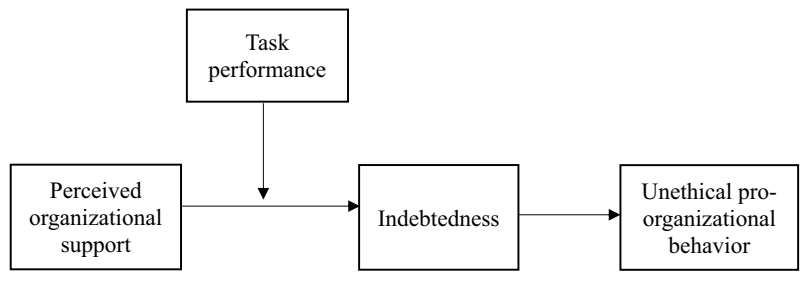

Fig. 1 Theoretical model

level of organizational support yet make limited work-related contributions (i.e., low task performance). In addition, our research underscores the importance of taking a balanced view from the perspectives of both the organization and the employee when scrutinizing the social exchange perspective on UPB. We therefore more precisely and comprehensively examine social exchange relationships between employees and the organization and provide in-depth understanding of why and under what conditions UPB becomes the most likely choice for employees to reciprocate positive social exchange relationships. Finally, we contribute to the UPB literature by enriching knowledge of the cognitive-motivational mechanisms that underlie UPB by poor performers. The extant research drawing on the social exchange perspective on UPB exclusively focuses on the psychological process of moral neutralization or disengagement (Bryant \& Merritt, 2019; Wang et al., 2019). Our research advances this stream of work by identifying felt indebtedness as another psychological mechanism that is in addition to previously identified mechanisms to explain a strong and urgent desire on the part of poor performers to engage in UPB to 'pay off their debts.' Taken together, our research contributes to the UPB literature by providing more nuanced insights into understanding when and why positive social exchanges between employees and the organization will lead to UPB.

\section{Theory and Hypotheses}

\section{The Social Exchange Perspective on UPB}

Social exchange is a dynamic and reciprocal process in which two parties who are both investors and receivers follow reciprocity norms to repay the resources (e.g., kindness, favors or support) they receive from the other (Blau, 1964; Cropanzano \& Mitchell, 2005; Emerson, 1976; Gouldner, 1960). In employee-organization social exchange relationships, both organizations and employees invest their resources in their relationship and expect the other party to reciprocate with their desired outputs. Previous research in the UPB literature has predominantly focused on the organizational perspective-regarding organizations as investors and employees as receivers-and theorized that 
employees engage in UPB to reciprocate positive exchanges with the organization. For example, high-inducement employee-organization relationships (Wang et al., 2019), high-performance work systems (Xu \& Lv, 2018), affective organizational commitment (Matherne III and Litchfiled, 2012) and workplace spirituality (Zhang, 2020) have all been found to be positively associated with employee UPB. Similarly, as leaders are representatives of organizations, Bryant and Merritt (2019) have recently found a positive association between leader-member exchange and supervisor-focused UPB. However, employees may also invest in exchange relationships based on their perceptions of their personal inputs and outputs, and the employee perspective has been surprisingly overlooked. This omission is problematic as the question still remains of why employees choose to reciprocate their organization's high inducements by engaging in UPB instead of making more legitimate and desirable contributions at work, such as increased work effort and task performance (Mathieu \& Zajac, 1990; Meyer \& Allen, 1997; Mowday et al., 1982). Therefore, investigating UPB from the organizational perspective can no longer advance our understanding of the motivational mechanisms that underlie UPB.

In this paper, we argue that UPB will only occur when employees perceive their inputs to be inadequate in the exchange relationship with their organization and then look for a shortcut to reciprocate to the organization. From the employees' perspective, they input their task performance in the exchange relationship with their organization and receive their desired salary, status, achievement, etc. Only when they perceive their inputs to be below the organizational expectation, e.g., low-performance, may they be driven to find other ways to maintain reciprocity norms in social exchange processes. In this case, a shortcut that enables them to reciprocate to their organization quickly will become more attractive. In the present paper, we combine two perspectives, those of organizations and of employees, to provide a more comprehensive picture to advance our knowledge of motivations behind UPB.

\section{The Interaction Between Perceived Organizational Support and Task Performance}

How positive the exchange relationships between employees and organizations are is reflected in the extent to which employees have a general perception that their organization values their contribution and cares about their wellbeing: perceived organizational support (POS, Eisenberger et al., 1986; Kurtessis et al., 2017; Rhoades \& Eisenberger, 2002). According to the norm of reciprocity, employees who perceive high organizational support tend to feel obliged to reciprocate to their organization by contributing to its goals (Cassar \& Briner, 2011; Eisenberger, Fasolo, \& Davislamastro, 1990; Wayne, Shore, \& Liden, 1997), including by increasing their organizational commitment, job involvement, performance and desire to remain, and decreasing withdrawal behavior (for a meta-analysis review, see Rhoades \& Eisenberger, 2002). If they fail to reciprocate, they may feel indebted to the organization (Peng, Nelissen, $\&$ Zeelenberg, 2018; Turnley et al., 2003).

From employees' perspectives, task performance and UPB are among the ways to reciprocate to organizations, both of which can benefit the organization or protect it from losses to some extent. Effectively carrying out formally prescribed job responsibilities (Turnley et al., 2003) and performing well on core tasks is the fundamental way in which employees can contribute to the organization (Tsui et al., 1997). Consequently, employees will use their level of task performance as an initial and key reference to evaluate the extent to which they reciprocate their perceived organizational support. Indeed, prior studies have shown that perceived organizational support is positively related to employee performance as a way to reciprocate organizational support (for a meta-analysis review, see Kurtessis et al., 2017). When they achieve high levels of task performance, employees will probably perceive that they have effectively fulfilled their employment obligations and have successfully reciprocated the organizational support they have received (Eisenberger et al., 1986; Rousseau \& McLean Parks, 1993). Compared to a high level of task performance, engaging in UPB requires employees to pay huge personal costs because complying with ethical norms is important for individuals to maintain their positive self-concept (Greenwald, 1980; Griffin \& Ross, 1991; Sanitioso, Kunda, \& Fong, 1990). Therefore, when employees achieve a high level of performance on work tasks, it is not necessary for them to violate their moral standards to maintain reciprocity norms and therefore it is unlikely they will engage in UPB to reciprocate to their organization.

In contrast, employees whose performance is poor may feel it is necessary to urgently reciprocate to the organization because they have not fulfilled their obligations. Specifically, although employees who have received organizational rewards and favorable treatment (i.e., high perceived organizational support) are motivated to reciprocate by increasing their performance, not everyone can perform as well as they wish. In this case, low-performing employees will have a strong desire to find other ways to reciprocate to the organization so as to obey reciprocity norms. In particular, when they have perceived favorable treatment by the organization, the unfilled employment obligation may result in psychological discomfort such as self-blame (Shore \& Barksdale, 1998; Wayne et al., 1997). To avoid violating the norm of reciprocity, low performers who perceive a high level of organizational support will perceive an urgency to reciprocate and then are likely to pay more attention to the short-term effects of their actions than long-term impacts. In this case, UPB becomes a 'reasonable and appropriate' 
choice for employees to fulfill their employment obligation. We therefore propose the following:

Hypothesis 1 Perceived organizational support and task performance interact to predict UPB by employees so that the relationship between perceived organizational support and UPB will be more positive among employees with low task performance than among employees with high task performance.

\section{Felt Indebtedness as a Psychological Explanation}

Beyond understanding this proposed interactive effect on $\mathrm{UPB}$, it is also important to investigate the mediating process. Felt indebtedness is defined as "a state of obligation to repay another" (Greenberg, 1980, p. 4). Social exchange researchers have identified feelings of indebtedness as a common response after receiving organizational support but failing to reciprocate (Fisher, Nadler, \& Whitcher-Alagna, 1982; Gleason et al., 2008; Turnley et al., 2003). That is, feelings of indebtedness derive from the violation of reciprocity norms in social exchanges, which motivates individuals to adhere to the reciprocity norm by taking actions to pay their debts. Being perceived as socially insensitive may dampen individuals' self-esteem, compromise their autonomy and arouse anxiety (Fisher et al., 1982; Greenberg and Westcott, 1983; Xiong et al., 2018). As low-performing employees who have received organizational support and favorable treatment, they will probably feel uncomfortable about their indebtedness because they fail to reciprocate with a high level of task performance. To reduce these unpleasant feelings as quickly as possible, they will therefore have a strong and urgent desire to 'pay their debt,' which may lead them to focus on the short-term effects of their actions. In support of this argument, Fredrickson (2004, p. 160) states that indebtedness can be associated with a narrow tit-for-tat type of reciprocity. Since UPB can immediately benefit organizations (Umphress \& Bingham, 2011), it is reasonable and likely that employees who feel indebted to the organization may choose to reciprocate with UPB.

To summarize, when employees perceive a high level of organizational support, an unfulfilled obligation because of poor performance may lead to feelings of indebtedness and consequently a strong and urgent motivation to reduce this discomfort by engaging in UPB. Therefore, we present the following:

Hypothesis 2 Indebtedness to the organization mediates the interaction effect of perceived organizational support and task performance on unethical pro-organization behavior so that the indirect relationship between perceived organizational support and unethical pro-organization behavior via indebtedness to the organization will be more positive when task performance is low than when it is high.

\section{Research Overview}

To test our hypotheses, we conducted two empirical studies. Study 1 involved two measurement occasions with the interaction between perceived organizational support and task performance (Hypothesis 1) being measured at Time 1 and employee UPB measured at Time 2. We next conducted Study 2 to investigate the strength of the causal relationship of the interactive effect on employee UPB that was found in Study 1 and to test the full model, including the mediation effect of felt indebtedness (Hypothesis 2). As converging results emerged using different research methodologies and samples, we gained increased confidence in their validity and generalizability.

\section{Study 1}

\section{Methods}

\section{Sample and Procedure}

We obtained access to a Chinese pharmaceutical company located in Jiangsu Province which agreed to take part in our research. With the assistance of the HR manager, we sent an invitation email to all 418 of the company's salespersons in its four marketing branches which included a trackable link to the Time 1 questionnaire investigating perceived organizational support, task performance, demographic information (i.e., gender, age and organizational tenure) and social desirability. Among them, 317 respondents voluntarily completed the first-wave survey and agreed to be notified for the next survey. A month later, we sent the second-wave questionnaires to them to measure their UPB in the workplace. A total of 237 respondents completed the Time 2 survey, a response rate of $56.7 \%$. Three responses had missing values for our key variable (i.e., task performance) and so were excluded from our final dataset. Of the 234 valid responses, the average age was 31 years old $(\mathrm{SD}=5.80)$ and $57 \%$ were male. A total of $4.9 \%$ of the respondents had a high school qualification or below, $54.7 \%$ an associate degree and $41.5 \%$ a bachelor's degree. The average organizational tenure was 1.61 years $(\mathrm{SD}=.81)$.

\section{Measures}

The respondents gave their answers on seven-point Likert scales $(1=$ strongly disagree, $7=$ strongly agree $)$ for all the key variables in the study. The English scales were translated into Chinese following standard translation and retranslation procedures. 
Table 1 Confirmatory factor analysis of measurement models in Study 1

\begin{tabular}{llrrrrr}
\hline Model & Factor structure & \multicolumn{1}{c}{$\chi^{2}(\mathrm{df})$} & \multicolumn{1}{c}{$\Delta \chi^{2}$} & \multicolumn{1}{l}{ RMSEA } & CFI & SRMR \\
\hline Model 1 & POS, TP and UPB & $196.91(74)$ & & 0.08 & 0.95 & 0.04 \\
Model 2 & POS and UPB are combined & $456.20(76)$ & $259.29^{* * * *}$ & 0.15 & 0.84 & 0.10 \\
Model 3 & TP and UPB are combined & $511.92(76)$ & $315.01^{* * *}$ & 0.16 & 0.82 & 0.13 \\
Model 4 & POS and TP are combined & $943.27(76)$ & $746.36^{* * * *}$ & 0.22 & 0.64 & 0.19 \\
Model 5 & POS, TP, and UPB are combined & $1228.59(77)$ & $1031.68^{* * *}$ & 0.25 & 0.52 & 0.21 \\
\hline
\end{tabular}

In determining adjusted $\Delta \chi^{2}$, all alternative models were compared with the baseline model, i.e., Model 1 $P O S$ perceived organizational support, $T P$ task performance, $U P B$ unethical pro-organizational behavior $* * * p<0.001$ (two-tailed)
Perceived Organizational Support We used a revised seven-item version of the scale developed by Lambert (2000). Example items are "the company attaches great importance to my personal goals and values" and "the company attaches great importance to my quality of life." Cronbach's $\alpha=.94$.

Task Performance Our measure of task performance used the four-item scale recommended by Meyer, Allen and Smith (1993). Example items are "I dutifully perform the duties assigned to me by the company" and "I perform all the duties required by the position." Cronbach's $\alpha=.92$.

Unethical Pro-organizational Behavior To construct a sales-specific measure of UPB, we modified the six-item scale developed by Umphress, Bingham and Mitchell (2010). Since our participants' jobs were selling medicine to hospitals, we deleted one item from the original scale, which was "Since my organization needed me to, I gave a good recommendation on behalf of an incompetent employee in the hope that the person will become another organization's problem instead of our own." In addition, we added three items relevant to their daily work, which were "Since it would help my organization, I exaggerated the effects of my company's medicine when selling to customers and clients," "Since it would help my organization, I withheld the side effects of my company's medicine from customers and clients" and "Since it would reduce difficulties for my organization, I attempted to sell the worst-selling medicine to customers and clients." The UPB scale had eight items ( $1=$ Never, $7=$ Always $)$, which can be found in the "Appendix". Cronbach's $\alpha=.86$.

\section{Control Variables}

Previous research suggests that employees' gender, age, education level and organizational tenure may affect UPB (Thau et al., 2015; Umphress et al., 2010) so we controlled for these variables. To account for participants' tendency to respond to UPB items in a socially desirable way (Chen,
Chen, \& Sheldon, 2016; Umphress et al., 2010), we measured a subscale for social desirability (Steenkamp, De Jong, \& Baumgartner, 2010) (Cronbach's $\alpha=$.76).

\section{Results}

\section{Confirmatory Factor Analyses (CFAs)}

We first conducted CFAs using Mplus 8.0 (Muthén \& Muthén, 2012-2017) to examine the discriminant validity of the key measures used in this study: perceived organizational support, task performance and UPB. Three-item parcels with random item assignment were used as indicators of latent UPB to improve the ratio of the sample size to the number of freely estimated parameters (Hall, Snell, \& Foust, 1999; Little et al., 2002). The results are reported in Table 1. As the table shows, the proposed measurement model (Model 1) had the best fit among all the models $\left[\chi^{2}(74)=196.91, \mathrm{CFI}=.95, \mathrm{RMSEA}=.08, \mathrm{SRMR}=.04\right]$. The standardized loadings of all the indicators on their specific constructs were significant at the .01 level. The alternative models (Models 2-5) had significantly worse fit than the baseline model, as can be seen from the $\chi^{2}$ difference tests and model fit indices. Therefore, the results of the CFAs supported the distinctiveness of the key measures in the study.

\section{Descriptive Statistics}

Descriptive statistics including the means, standard deviations and correlations are presented in Table 2 .

\section{Hypothesis Testing}

Hypothesis 1 proposed there would be an interaction effect between perceived organizational support and task performance on UPB. The results of the regression analyses are shown in Table 3. After controlling for gender, age, 
Table 2 Means, standard deviations, and intercorrelations between scales for Studies 1 and 2

\begin{tabular}{|c|c|c|c|c|c|c|c|c|c|c|}
\hline & Mean & SD & 1 & 2 & 3 & 4 & 5 & 6 & 7 & 8 \\
\hline \multicolumn{11}{|l|}{ Study $1(N=234)$} \\
\hline 1. Age & 31.00 & 5.80 & & & & & & & & \\
\hline 2. Gender & 0.57 & 0.50 & -0.10 & & & & & & & \\
\hline 3. Education & 3.35 & 0.64 & $-0.22 * *$ & $0.18 * *$ & & & & & & \\
\hline 4. Tenure & 1.61 & 0.81 & $0.67 * *$ & -0.04 & -0.07 & & & & & \\
\hline 5. SD & 5.73 & 0.73 & 0.09 & $-0.22 * *$ & $-0.18 * *$ & 0.06 & & & & \\
\hline 6. UPB & 3.28 & 1.20 & -0.11 & 0.11 & -0.03 & -0.06 & $-0.33 * *$ & & & \\
\hline 7. POS & 5.66 & 1.10 & 0.04 & -0.04 & $-0.13 *$ & -0.02 & 0.09 & 0.08 & & \\
\hline 8. TP & 5.71 & 1.02 & $0.16^{*}$ & -0.03 & -0.10 & $0.14 *$ & $0.34 * *$ & $-0.33 * *$ & $0.16^{*}$ & \\
\hline 9. $\mathrm{POS} * \mathrm{TP}$ & 0.18 & 1.16 & -0.01 & -0.09 & 0.11 & 0.01 & 0.12 & $-0.23 * *$ & 0.00 & $0.26 * *$ \\
\hline \multicolumn{11}{|l|}{ Study $2(N=348)$} \\
\hline 1. Age & 33.57 & 6.95 & & & & & & & & \\
\hline 2. Gender & 0.50 & 0.50 & $-0.16^{* *}$ & & & & & & & \\
\hline 3. Education & 3.94 & 0.56 & $-0.12 *$ & -0.03 & & & & & & \\
\hline 4. Tenure & 7.57 & 6.01 & 0.10 & -0.06 & 0.00 & & & & & \\
\hline 5. POS & 1.53 & 0.50 & 0.04 & -0.04 & 0.001 & -0.06 & & & & \\
\hline 6. ТP & 1.50 & 0.50 & 0.04 & 0.02 & 0.01 & -0.05 & $0.20 * *$ & & & \\
\hline 7. Indebtedness & 5.07 & 1.33 & 0.09 & -0.03 & 0.01 & -0.05 & $0.67 * *$ & -0.002 & & \\
\hline 8. UPB & 1.33 & 0.47 & -0.05 & 0.002 & 0.05 & 0.07 & 0.05 & -0.06 & $0.16^{* *}$ & \\
\hline 9. $\mathrm{POS} * \mathrm{TP}$ & 2.34 & 1.19 & 0.06 & -0.03 & -0.03 & -0.01 & $0.75^{* *}$ & $0.76^{* *}$ & $0.39 * *$ & -0.03 \\
\hline
\end{tabular}

Gender: $\mathrm{M}=1, \mathrm{~F}=0$

$P O S$ perceived organizational support, $T P$ task performance, $U P B$ unethical pro-organizational behavior, $S D$ social desirability ${ }^{*} p<.05, * * p<.01, * * * p<.001$ (two-tailed)

Table 3 Regression results in Study 1

\begin{tabular}{|c|c|c|c|c|c|c|c|c|}
\hline \multirow[t]{3}{*}{ Variables $(N=237)$} & \multicolumn{8}{|l|}{ UPB } \\
\hline & \multicolumn{2}{|l|}{ Model 1} & \multicolumn{2}{|l|}{ Model 2} & \multicolumn{2}{|l|}{ Model 3} & \multicolumn{2}{|l|}{ Model 4} \\
\hline & $B$ & SE & $B$ & SE & $B$ & SE & $B$ & SE \\
\hline Gender & 0.11 & 0.16 & 0.15 & 0.15 & 0.12 & 0.02 & & \\
\hline Age & -0.03 & 0.02 & -0.03 & 0.02 & -0.03 & 0.15 & & \\
\hline Education & $-0.24 *$ & 0.12 & -0.22 & 0.12 & -0.19 & 0.12 & & \\
\hline Tenure & 0.08 & 0.13 & 0.11 & 0.12 & 0.11 & 0.12 & & \\
\hline Social desirability & $-0.55^{* * *}$ & 0.11 & $-0.41 * * *$ & 0.11 & $-0.40 * * *$ & 0.11 & & \\
\hline POS & & & $0.15^{*}$ & 0.07 & $0.14 *$ & 0.07 & $0.14 *$ & 0.07 \\
\hline Task performance & & & $-0.31 * * *$ & 0.08 & $-0.27 * *$ & 0.08 & $-0.37 * * *$ & 0.08 \\
\hline $\mathrm{POS} * \mathrm{TP}$ & & & & & $-0.13^{*}$ & 0.07 & $-0.16^{*}$ & 0.07 \\
\hline$R^{2}$ & 0.13 & 0.20 & 0.21 & & & & & \\
\hline$\Delta R^{2}$ & & & $0.07 * * *$ & & $0.02 *$ & & & \\
\hline
\end{tabular}

$P O S$ perceived organizational support, $T P$ task performance

$* p<0.05, * * p<0.01, * * * p<0.001$ (two-tailed) education level, organizational tenure and social desirability, employees' perceived organizational support was positively related to UPB in the workplace $(B=.15, \mathrm{SE}=.07, p=.03$, Model 2) and task performance was negatively related to UPB $(B=-.31, \mathrm{SE}=.08, p<.001$, Model 2$)$. When the interaction term between perceived organizational support and task performance entered the regression equation, the regression coefficient was significant $(B=-.13, \mathrm{SE}=.07$, $p=.04$, Model 3), which supports Hypothesis 1 . The results for Model 4 showed the same pattern and level of significance when the control variables were excluded. In addition, post hoc power analysis using GPower 3.1 (Faul et al., 2007) 


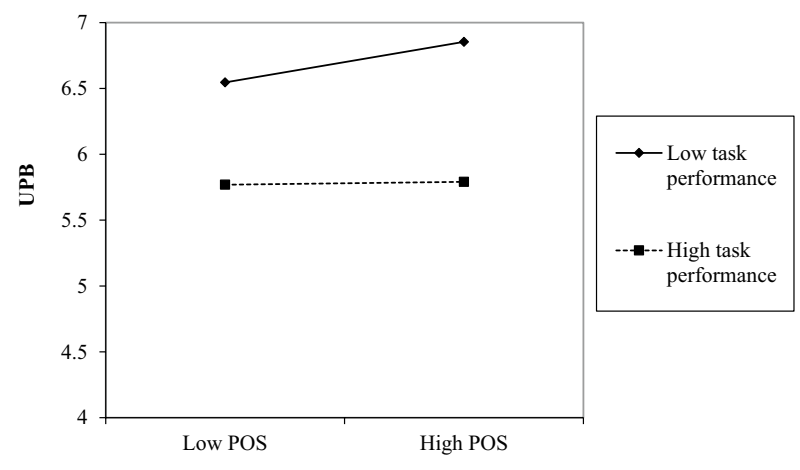

Fig. 2 The interactive effect of perceived organizational support and task performance on UPB in Study 1

indicated that the power to detect obtained effects at the .05 level was .99 the overall regression in prediction of UPB.

To better demonstrate the interactive effect between task performance and perceived organizational support on UPB, we plotted a graph of the moderating effect. As Fig. 2 reveals, when task performance was low (1 standard deviation below the average), employees' perceived organizational support was significantly positively correlated with their unethical pro-organizational behavior $(B=.28$, $\mathrm{SE}=.09, p<.01)$. When task performance was high $(1$ standard deviation above average), the relationship was not significant ( $B=.01, \mathrm{SE}=.09$, n.s.). This further supports the hypothesis that perceived organizational support and task performance interact to predict employee UPB in the workplace and provides field evidence for our research.

Although Study 1 with a time-lagged design provides support for our interactive hypothesis in a practical context, it is nevertheless important to note some limitations. First, this field study was unable to examine a causal relationship between the interaction and UPB because both variables are measured rather than manipulated, making the results correlational. In addition, we did not test for the mediating role of indebtedness in our model. Therefore, we conducted a scenario experiment to address the causality and examine a mediated moderation model.

\section{Study 2}

\section{Method}

\section{Participants and Design}

After reading and signing a consent form, 348 full-time employed participants were recruited through an online platform (https://www.wjx.cn/) which is equivalent to Amazon Mechanical Turk. The instructions and questionnaire were presented in Chinese. The participants were aged between 18 and 60 and employed in organizations. $49.7 \%$ of the participants were male. They had an average age of 33.57 years $(\mathrm{SD}=6.95)$ and an average organizational tenure of 7.57 years $(\mathrm{SD}=6.01)$. Among the participants, $2 \%$ had a high school certificate, $10.9 \%$ a higher education certificate, $77 \%$ a bachelor's degree and $10 \%$ a postgraduate degree.

This study used a 2 (perceived organizational support: high vs. low) by 2 (task performance: high vs. low) design. The participants were randomly assigned to one of four experimental conditions. On average, they took nine minutes to complete the whole experiment and received $¥ 13$ (equivalent to \$1.89) for their efforts. They were asked to carefully read the following scenario and to imagine how they would feel and think in the situation.

Tengfei Electric Manufacturing Co. Ltd. was founded in March 2008. It is a medium-sized household appliance manufacturer with 1500 employees. After several rounds of interviews, you succeeded in joining Tengfei's sales department. According to company policy, your sales performance will not have a significant impact on your remuneration. ${ }^{1}$ As a sales representative, your responsibilities include collecting current market data, maintaining customer loyalty, developing markets and gaining new orders.

\section{Perceived Organizational Support}

The participants in the high (low) perceived organizational support condition read the following scenario:

This year, Tengfei was rated one of the 500 most (least) popular companies among employees in China. You and most of your colleagues agree that Tengfei gives (doesn't give) you much care and attention and is (isn't) very concerned about the welfare of employees. Employees can (cannot) seek and get help from the company when they are in trouble. The company will (never) try its best to improve the working conditions of employees when they have requirements. In addition, the company also cares (doesn't care) about the opinions of employees and (never) takes each employee's personal goals and values into consideration when formulating company policies.

\footnotetext{
${ }^{1}$ We presented the company policy to decouple the relationship between task performance and direct personal interest. The statement aims to rule out the possibility that participants engage in UPB only to achieve higher remuneration by enhancing their performance.
} 


\section{Task Performance}

Then, the participants saw their individual levels of task performance. Participants with high task performance were ranked in the top 10-30\% for each of the four quarters, while those with low work performance were ranked in the bottom 10-30\% (see the table below).

Sales ranking this year

\begin{tabular}{ll}
\hline & Ranking \\
\hline 1st quarter (months 1-3) & Top (Bottom) 10\% \\
2nd quarter (months 4-6) & Top (Bottom) 30\% \\
3rd quarter (months 7-9) & Top (Bottom) 20\% \\
4th quarter (months 10-12) & Top (Bottom) 10\% \\
\hline
\end{tabular}

\section{Indebtedness}

We used four items from Shen, Wan and Wyer Jr (2011). The items are "I feel indebted to my company," "I feel like I owe my company something," "I feel uncomfortable about owing my company" and "I feel obliged to return a favor to Tengfei." Cronbach's $\alpha=.94$.

\section{Unethical Pro-organizational Behavior}

To measure actual participant behavior rather than selfreported behavioral willingness, we asked participants to read the following brief scenario in which they were clearly informed about a serious product problem and the importance of sales deals for their company. After reading the situation, participants were asked to choose whether to conceal the negative truth from the potential buyer to benefit the company.

Recently, you have been assigned to negotiate with a potential international buyer in Europe which is likely to order new-model refrigerators with a value of five million RMB. After a few rounds of online negotiation with the European buyer, you are informed that your prices are very competitive compared with two other firms competing for the same order. You have a feeling that the buyer is leaning toward your company, but they have requested a meeting with you to learn more about some specific product features. While the new models are generally of superior quality, you recently learned from the head of the manufacturing department about a serious problem with this model. While it maintains a high level of energy efficiency in the first few years, the efficiency will deteriorate afterwards as the machine gets older. It is up to you whether or not to disclose this undesirable information. If you disclose this information to the buyer, the deal will probably go to one of your competitors and Tengfei will lose one of the largest sales deals in its recent history. You are scheduled to meet the buyer tomorrow and you are still debating whether or not to conceal this information from the buyer. What will you do (1- I will disclose to the buyer the newly learned energy consumption information; 0- I will conceal the negative truth from the potential buyer to complete the deal)?

\section{Manipulation Checks}

After reading the context about perceived organizational support and task performance, the participants were asked to respond to their performance ranking in the third quarter (top $20 \%$ vs. bottom $20 \%$ ) and how the company treated employees (Tengfei gives employees much care and attention vs. Tengfei gives employees little care and attention). If they did not choose the option which matches the context, the test was automatically terminated and the participant was excluded from the final sample.

\section{Results}

\section{Hypothesis Testing}

The descriptive statistics are presented in Table 2. Binary logistic regression was used to examine the main effects of perceived organizational support and task performance on UPB and the interactive effect between perceived organizational support and task performance on UPB (H1). A twoway ANOVA was performed to examine the main effect and the interaction effect between POS and task performance on indebtedness. Next, we examined the conditional mediating effect in the high and low task performance conditions (H2). The statistical significance of these conditional mediating effects was examined by inspecting bootstrapped $95 \%$ confidence intervals (5000 bootstrap samples) around the indirect effect estimates.

\section{Unethical Pro-organizational Behavior}

The results of a binary logistic regression showed that the main effect of perceived organizational support on UPB was non-significant, $B=.22$, n.s. Slightly more participants in the low-performance condition $(N=62,35.63 \%)$ than in the high-performance condition $(N=53,30.46 \%)$ indicated UPB. Similar findings were found with respect to the main effect of task performance, $B=-.23$, n.s. Slightly more participants in the high-POS condition $(N=65,35.33 \%)$ than in the low-POS condition $(N=50,30.49 \%)$ indicated 


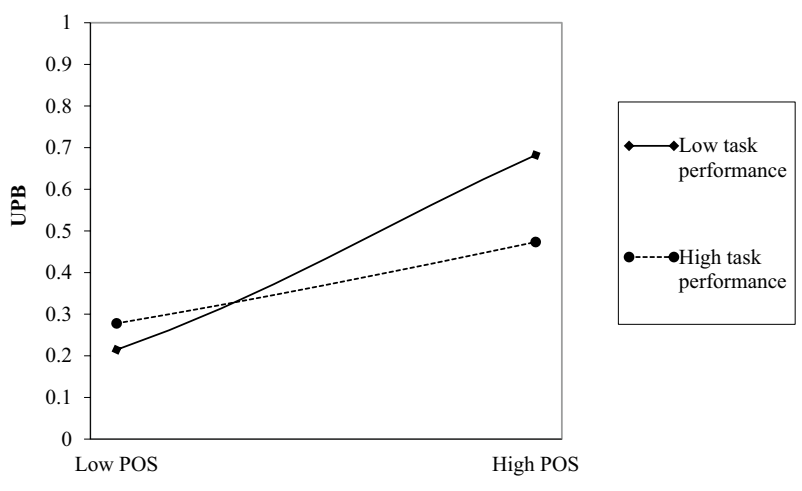

Fig. 3 The interactive effect of perceived organizational support and task performance on UPB in Study 2

UPB. However, the binary logistic regression suggested a statistically significant interaction effect, $B=-1.21, p<.01$. The interaction pattern is plotted in Fig. 3. The interaction indicated a stronger positive relationship between perceived organizational support and UPB when task performance was low than when it was high. Specifically, in the high-POS and low task performance condition, 35 participants (46.67\%) indicated UPB, 27 participants (27.27\%) chose UPB in the low-POS and low task performance condition, 30 participants $(27.52 \%)$ chose UPB in the high-POS and high task performance condition and 23 participants (35.38\%) chose UPB in the high-performance and low-POS condition.

\section{Indebtedness}

The results of the ANOVA showed a positive main effect of perceived organizational support on feelings of indebtedness $\left[F(1,344)=305.32, p<.001, \eta^{2}=.47\right]$. The participants had a significantly higher level of indebtedness in the high-POS condition $(M=5.97, \mathrm{SD}=.73)$ than in the low-POS condition $(M=4.12, \mathrm{SD}=.08)$. The results also showed a negative main effect of task performance on indebtedness $\left[F(1,344)=10.93, p<.001, \eta^{2}=.03\right]$. The participants had a significantly higher level of indebtedness in the low-TP condition $(M=5.21, \mathrm{SD}=.07)$ than in the high-TP condition $(M=4.87, \mathrm{SD}=.08)$. In addition, the ANOVA results also showed a significant interactive effect on indebtedness, $F(1,344)=7.95, p<.01$, $\eta^{2}=.02$. There was a stronger positive relationship between perceived organizational support and indebtedness to the organization when task performance was low than when it was high (see Fig. 4). In addition, post hoc power analysis using GPower 3.1 (Faul et al., 2007) indicated that the power to detect obtained effects at the .05 level was 1.00 for the overall regression in prediction of indebtedness. When task performance was low, perceived organizational support significantly influenced

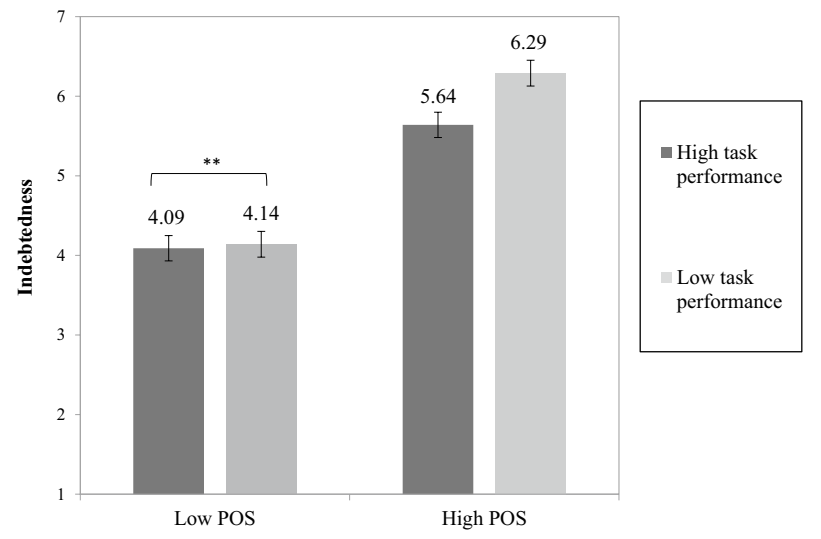

Fig. 4 The interactive effect of perceived organizational support and task performance on felt indebtedness in Study 2

feelings of indebtedness $\left(M_{\text {low-POS }}=4.14\right.$, and 95\% CI $[3.95,4.33]$ vs. $M_{\text {high-POS }}=6.29$ and $95 \%$ CI $[6.07,6.51]$, $p<.001$ ), whereas when task performance was high the impact of perceived organizational support on feelings of indebtedness was considerably weaker albeit significant $\left(M_{\text {low-POS }}=4.09\right.$ and $95 \%$ CI $[3.86,4.33]$ vs. $M_{\text {high-POS }}=5.64$ and $95 \%$ CI $\left.[5.46,5.83], p<.001\right)$. The interaction pattern is plotted in Fig. 4.

Next, we examined the mediated moderation effect using Mplus (Muthén \& Muthén, 2016). As expected, the unstandardized conditional indirect effect of perceived organizational support on unethical pro-organizational behavior via indebtedness was stronger when task performance was low $(B=.47, \mathrm{SE}=.16,95 \% \mathrm{CI}[.15, .78]$, excluding zero) than when it was high $(B=.30, \mathrm{SE}=.09,95 \% \mathrm{CI}[.12, .48]$, excluding zero). The difference in the indirect effect between the low and high task performance conditions was significant $(B=.17, \mathrm{SE}=.10, \mathrm{CI}[.03, .41]$, excluding zero). Therefore, Hypothesis 2 is also supported.

To sum up, in Study 2 we replicated the result that perceived organizational support and task performance had significant interaction effects on UPB, which supports H1. In addition, Study 2 also tested the mediated moderation hypothesis and the results showed that the indirect relationship between perceived organizational support and UPB via felt indebtedness to the organization is more positive when task performance is low than when it is high. Therefore, $\mathrm{H} 2$ is also supported.

\section{Discussion}

Drawing on social exchange theory (Blau, 1964), we have proposed and examined an interactive model to investigate the antecedents of and psychological mechanism behind UPB. We have found that perceived organizational support 
and employee performance interact to influence employee UPB. Low-performing employees who perceive high levels of organizational support are more likely to engage in UPB. This interplay effect can be explained by feelings of indebtedness to the organization-a mediator that has been first proposed and empirically tested in our research. Our hypotheses have been supported by two empirical studies: a time-lagged field study to investigate the interactive effects of perceived organizational support and employee performance on UPB; and an experimental study where these two antecedents are manipulated to investigate a moderated mediation model to demonstrate the role of indebtedness in the overall framework. The findings indicate that employees who perceive organizational support will engage in UPB only when they cannot achieve good performance. Our research has both theoretical and practical implications, which we outline in the following sections.

\section{Theoretical Implications}

Our findings have theoretical implications for the streams of literature on UPB and performance management in several ways. First, by studying the boundary condition of employee performance on the effect of perceived organizational support on UPB, we enrich understanding of the effect of positive exchanges in the UPB literature. Previous studies have predominantly focused on positive effects of exchange relationships with the organization as antecedents of UPB, and the limitation of situational factors has been largely overlooked. These factors are especially important in ethical decisions in organizational settings (Kish-Gephart, Harrison, \& Treviño, 2010). Therefore, it is surprising and problematic that little research in the existing literature focuses on boundary conditions in the UPB decision process. Our results highlight the importance of employee performance in employees' decisions to reciprocate to the organization by engaging in UPB. Specifically, since performing well on core tasks is the fundamental way for employees to fulfill their responsibilities and reciprocate to the organization (Tsui et al., 1997), high-performing employees have little motivation to choose UPB while employees who perform poorly are more likely to engage in UPB to reciprocate perceived organizational support. As one of the first papers to present and examine the value of task performance in influencing UPB, our research extends understanding of UPB as 'the downside of positive exchanges.' Future research can extend our findings and explore other conditional factors that limit the effects of positive exchanges.

In addition, our studies are among the first to propose and empirically examine feelings of indebtedness as the cognitive mechanism that underlies the UPB decision process, thus providing a complete picture of the process of engaging in UPB from the actor's perspective. Traditional
UPB mechanisms emphasize the moral justification process (e.g., moral disengagement, Chen et al., 2016; neutralization, Umphress \& Bingham, 2011) with which employees who intend to positively reciprocate to the organization persuade themselves to do so in unethical ways. Previous studies leave unanswered the important question of how employees think about the necessity of UPB in their decision-making process. The present studies answer the question by finding feelings of indebtedness to be the mediator between the interaction pattern and UPB. Therefore, although some scholars have proposed that indebtedness is a negative experience (Fisher et al., 1982; Greenberg and Westcott, 1983; Xiong et al., 2018), not only are we the first to apply this finding in the UPB literature but we have investigated the cognitive process when actors balance their inputs and outputs in the exchange relationship with the organization.

Last but not least, by studying the moderating effect of task performance, we have added to the growing understanding of the outcomes of employee performance in work contexts. Although it is one of the main outcome variables that have been investigated in the field of organizational behavior, not much existing research has investigated employee performance as an antecedent. However, given that employee performance has been found to also have some effects on workplace interpersonal relationships (e.g., Khan et al., 2018; Kim \& Glomb, 2014), we have enriched the existing literature and found the effect of employee performance on UPB. More importantly, we have investigated the influence of self-perceived rather than objective or otherevaluated performance in work contexts. Although the latter two have more implications in practice as outcomes, our findings suggest that employees' subjective perceptions of their task performance have an influence on their subsequent work behavior. Therefore, it is especially important to direct low-performing employees to make a contribution in ethical and beneficial ways. This also indicates a new direction for future research on performance management.

\section{Implications for Practice}

Based on our finding that employees' perceived organizational support may not increase their UPB unless they have lowperformance, and that it is indebtedness rather than perceived organizational support itself that facilitates employee UPB, we recommend that organization managers should pay more attention to avoid low performers seeing UPB as a way to reciprocate to the organization and also provide them with more opportunities to reciprocate organizational support by enhancing their performance on work tasks. Although at first employee UPB may give rise to immediate benefits for their companies, the unethical issues will finally be exposed and these actions will cause severe losses of organizational interest and reputation in the long run (Umphress \& Bingham, 
2011). For example, Boeing employees concealed fatal flaws in the 737 Max planes to help the company maintain profitability, which resulted in aviation accidents involving the deaths of hundreds of people and also put Boeing into bankruptcy crisis (Larris, 2019; MacMillan, 2019). Nevertheless, UPB is carried out with a 'pro-organizational' intention, indicating that actors may not realize the long-term consequences of their unethical actions. Therefore, organizational decision-makers should pay more attention to monitoring such employee behavior and inhibit such acts by highlighting the importance of ethical values and clarifying the severe consequences of UPB for organizations such as through conducting regular business ethics seminars. By doing so, they can make their employees clearly aware of the monetary and reputational losses their unethical work behavior might result in, and then those who authentically want to reciprocate to their organizations will be more likely to avoid UPB in their everyday organizational activities. Second, because perceived organizational support is also shown to be positively related to higher employee performance (e.g., Shanock \& Eisenberger, 2006), organizational managers should provide more opportunities for employees to develop their work competence and improve their task performance, for example by conducting competence-developing workshops. After all, performing well on core tasks is the fundamental way for employees to reciprocate to the organization (Tsui et al., 1997; Turnley et al., 2003). If employees feel increasingly competent to enhance their performance, their willingness to reciprocate should also be directed to performance improvement and the likelihood of them engaging in UPB should therefore decrease.

\section{Limitations and Future Research}

Our study is not without its limitations, as a result of which we suggest several future research directions. First, our research has focused on UPB among salespersons, which might be a little different from UPB in other occupations, in which case employees may have fewer chances and less autonomy to engage in UPB. Sales is a unique profession in that salespersons have a high degree of autonomy and independence to deal with their work and it is easier for them to know what benefits they can bring to the organization (i.e., sales numbers). It might be the case that the allure of UPB can be more clearly seen by salespersons than those in other professions and that it is their higher likelihood of engaging in UPB that leads to them doing so rather than individual-level factors. Therefore, we suggest that future research will benefit from investigating whether the interaction pattern can be extended to other industries. We also call for more future research to investigate whether and how job autonomy influences employee UPB.

In addition, the two samples in our empirical studies were both full-time Chinese employees so cultural homogeneity may affect the generalizability of our findings. Because collectivism predominates in Chinese culture, employees in Chinese organizations may put an emphasis on contributing to the organization in the workplace (Francesco \& Chen, 2004). In this context, awareness of low-performance but a perception of organizational support are more likely to create feelings of indebtedness and anxiety about the organization. Therefore, whether the interplay in our results can be generalized to organizations with Western cultures remains an open question. However, the downsides of indebtedness and UPB were first found in studies conducted in Western cultures (e.g., indebtedness in Watkins et al. 2006, UPB in Umphress \& Bingham, 2011). These findings suggest that the positive relationship between indebtedness and UPB in more individualist cultures may also be at play, but future research is needed to verify this.

Our research has common method variance (CMV) issues in terms of research design as all the key variables were rated by the employees. Although according to Siemsen, Roth and Oliveira (2010) and Lai, Li and Leung (2013) interaction effects cannot be an artifact of CMV and are more difficult to detect through statistical tests as interaction terms are deflated by CMV and the result of significant interaction effects of POS and task performance indicates that our findings are less likely to be a result of CMV, future research will benefit from replicating our findings using a longitudinal research design with multiple sources (i.e., both managers and employees) and cross-lagged modeling to examine the causal relationships proposed in our theoretical model.

Last but not least, future research may benefit from investigating the relationship between feeling indebtedness and guilt, and how they are related with UPB. Guilt is an emotional reaction to a negative event (such as the severe consequences of particular unethical deeds) (Eisenberg, 2000). According to the cognitive appraisal theory of emotion (Lazarus, 1991), which suggests that cognitive appraisal of certain person-environment relationships activates specific emotions, we posit that low-performance is a negative event that can trigger employees' cognitive appraisals of the relationship between the organization and feeling indebtedness, which in turn result in a feeling of guilt. In addition, in Umphress and Bingham (2011)'s UPB model, guilt and UPB have a reciprocal relationship where UPB leads to guilt and guilt inhibits UPB. It would be worth future research investigating whether felt indebtedness and UPB have a reciprocal relationship, that is, whether indebtedness can lead to UPB and UPB may reduce feelings of indebtedness.

\section{Appendix: Scale of UPB}

1. Since it would help my organisation, I exaggerated the truth about my company's products or services to customers and clients. 
2. Since it would help my organisation, I misrepresented the truth to make my organisation look good.

3. Since it would benefit my organisation, I withheld negative information about my company or its products from customers and clients.

4. Since my organisation needed me to, I concealed information from the public that could be damaging to my organisation.

5. Since my organisation needed me to, I withheld issuing a refund to a customer or a client accidentally overcharged.

6. Since it would help my organisation, I exaggerated the effects of my company's medicine on treatment to customers and clients.

7. Since it would help my organisation, I withheld the side effects of my company's medicine from customers and clients.

8. Since it would reduce the burden of my organisation, I attempted to sell the worst-selling medicine to customers and clients.

Funding This work was supported by the China Postdoctoral Science Fund (No. 2019M661639) to the first author, support by "Advancing Leadership Research" (W911NF-18-2-0049) U.S. Army Research Institute for the Behavioral and Social Sciences (ARI) to the second author; and supported by NSFC Key Project (No. 71832007) to the third author.

Data Availability The final dataset that support the findings of this study are available from the corresponding author, upon reasonable request.

Open Access This article is licensed under a Creative Commons Attribution 4.0 International License, which permits use, sharing, adaptation, distribution and reproduction in any medium or format, as long as you give appropriate credit to the original author(s) and the source, provide a link to the Creative Commons licence, and indicate if changes were made. The images or other third party material in this article are included in the article's Creative Commons licence, unless indicated otherwise in a credit line to the material. If material is not included in the article's Creative Commons licence and your intended use is not permitted by statutory regulation or exceeds the permitted use, you will need to obtain permission directly from the copyright holder. To view a copy of this licence, visit http://creativecommons.org/licenses/by/4.0/.

\section{References}

Bersoff, D. M. (1999). Why good people sometimes do bad things: Motivated reasoning and unethical behavior. Personality and Social Psychology Bulletin, 25, 28-39.

Blau, P. M. (1964). Exchange and power in social life. . New York: Routledge.
Bryant, W., \& Merritt, S. M. (2019). Unethical pro-organizational behavior and positive leader-employee relationships. Journal of Business Ethics, 168, 1-17.

Cassar, V., \& Briner, R. B. (2011). The relationship between psychological contract breach and organizational commitment: Exchange imbalance as a moderator of the mediating role of violation. Journal of Vocational Behavior, 78, 283-289.

Chen, M., Chen, C. C., \& Sheldon, O. J. (2016). Relaxing moral reasoning to win: How organizational identification relates to unethical pro-organizational behavior. Journal of Applied Psychology, 101, 1082-1096.

Cropanzano, R., \& Mitchell, M. S. (2005). Social exchange theory: An interdisciplinary review. Journal of Management, 31, 874-900.

Eisenberg, N. (2000). Emotion, regulation, and moral development. Annual Review of Psychology, 51(1), 665-697.

Eisenberger, R., Fasolo, P., \& Davislamastro, V. (1990). Perceived organizational support and employee diligence, commitment, and innovation. Journal of Applied Psychology, 75, 51-59.

Eisenberger, R., Huntington, R., Hutchison, S., \& Sowa, D. (1986). Perceived organizational support. Journal of Applied Psychology, 71, 500-507.

Emerson, R. M. (1976). Social exchange theory. Annual Review of Sociology, 2, 335-362.

Faul, F., Erdfelder, E., Lang, A-G., \& Buchner A. (2007). G*Power 3: A flexible statistical power analysis program for the social, behavioral, and biomedical sciences. Behavior Research Methods, 39(2), 175-191.

Fisher, J. D., Nadler, A., \& Whitcher-Alagna, S. (1982). Recipient reactions to aid. Psychological Bulletin, 91, 27-54.

Francesco, A. M., \& Chen, Z. X. (2004). Collectivism in action: Its moderating effects on the relationship between organizational commitment and employee performance in China. Group and Organization Management, 29, 425-441.

Fredrickson, B. L. (2004). Gratitude, like other positive emotions, broadens and builds. In R. A. Emmons \& M. E. McCullough (Eds.), The psychology of gratitude. (pp. 145-166). Oxford: Oxford University Press.

Gino, F., \& Ariely, D. (2012). The dark side of creativity: Original thinkers can be more dishonest. Journal of Personality and Social Psychology, 102, 445-459.

Gleason, M. E., Iida, M., Shrout, P. E., \& Bolger, N. (2008). Receiving support as a mixed blessing: Evidence for dual effects of support on psychological outcomes. Journal of Personality and Social Psychology, 94, 824-838.

Gouldner, A. W. (1960). The norm of reciprocity: A preliminary statement. American Sociological Review, 25, 161-178.

Greenberg, M. S. (1980). A theory of indebtedness. In K. J. Gergen, M. S. Greenberg, \& R. H. Willis (Eds.), Social exchange. (pp. 3-26). Boston: Springer.

Greenberg, M. S., \& Westcott, D. R. (1983). Indebtedness as a mediator of reactions to aid. New Directions in Helping, 1, 85-112.

Greenwald, A. G. (1980). The totalitarian ego: Fabrication and revision of personal history. American Psychologist, 35, 603-618.

Griffin, D. W., \& Ross, L. (1991). Subjective construal, social inference, and human misunderstanding. In M. P. Zanna \& J. M. Olson (Eds.), Advances in experimental social psychology. (Vol. 24, pp. 319-359). Cambridge, MA: Academic.

Hall, R. J., Snell, A. F., \& Foust, M. S. (1999). Item parceling strategies in SEM: Investigating the subtle effects of unmodeled secondary constructs. Organizational Research Methods, 2, 233-256.

Heider, F. (1958). The psychology of interpersonal relations. . New York: Wiley.

Johnson, H. H., \& Umphress, E. E. (2019). To help my supervisor: Identification, moral identity, and unethical pro-supervisor behavior. Journal of Business Ethics, 159, 519-534. 
Khan, A. K., Moss, S., Quratulain, S., \& Hameed, I. (2018). When and how subordinate performance leads to abusive supervision: A social dominance perspective. Journal of Management, 44, 2801-2826.

Kim, E., \& Glomb, T. M. (2014). Victimization of high performers: The roles of envy and work group identification. Journal of Applied Psychology, 99, 619-634.

Kish-Gephart, J. J., Harrison, D. A., \& Treviño, L. K. (2010). Bad apples, bad cases, and bad barrels: Meta-analytic evidence about sources of unethical decisions at work. Journal of Applied Psychology, 95, $1-31$.

Kurtessis, J. N., Eisenberger, R., Ford, M. T., Buffardi, L. C., Stewart, K. A., \& Adis, C. S. (2017). Perceived organizational support: A meta-analytic evaluation of organizational support theory. Journal of Management, 43, 1854-1884.

Lai, X., Li, F., \& Leung, K. (2013). A Monte Carlo study of the effects of common method variance on significance testing and parameter bias in hierarchical linear modeling. Organizational Research Methods, 16, 243-269.

Lambert, S. J. (2000). Added benefits: The link between work-life benefits and organizational citizenship behavior. Academy of Management Journal, 43, 801-815.

Larris, M. (2019). Long before the Max disasters, Boeing had a history of failing to fix safety problems. The Washington Post, June 27.

Lazarus, R. S. (1991). Emotion and adaptation. . New York: Oxford University Press.

Lee, A., Schwarz, G., Newman, A., \& Legood, A. (2019). Investigating when and why psychological entitlement predicts unethical proorganizational behavior. Journal of Business Ethics, 154, 109-126.

Little, T. D., Cunningham, W. A., Shahar, G., \& Widaman, K. F. (2002). To parcel or not to parcel: Exploring the question, weighing the merits. Structural Equation Modeling, 9, 151-173.

MacMillan, D. (2019). "Safety was just a given”: Inside Boeing' boardroom amid the 737 Max crisis. The Washington Post, May 6.

Matherne, C. F., III., \& Litchfield, S. R. (2012). Investigating the relationship between affective commitment and unethical pro-organizational behaviors: The role of moral identity. Journal of Leadership, Accountability and Ethics, 9, 35-46.

Mathieu, J. E., \& Zajac, D. M. (1990). A review and meta-analysis of the antecedents, correlates, and consequences of organizational commitment. Psychological Bulletin, 108, 171-194.

Meyer, J. P., \& Allen, N. J. (1997). Commitment in the workplace: Theory, research, and application. . London: Sage.

Meyer, J. P., Allen, N. J., \& Smith, C. A. (1993). Commitment to organizations and occupations: Extension and test of a three-component conceptualization. Journal of Applied Psychology, 78, 538-551.

Mowday, R. T., Porter, L. W., \& Steers, R. (1982). Organizational linkages: The psychology of commitment, absenteeism, and turnover. . San Diego, CA: Academic Press.

Muthén, L. K., \& Muthén, B. O. (2016). Mplus user's guide. (6th ed.). Los Angeles: Muthén and Muthén.

Peng, C., Nelissen, R. M., \& Zeelenberg, M. (2018). Reconsidering the roles of gratitude and indebtedness in social exchange. Cognition and Emotion, 32, 760-772.

Rhoades, L., \& Eisenberger, R. (2002). Perceived organizational support: A review of the literature. Journal of Applied Psychology, 87, 698-714.

Rousseau, D. M., \& McLean Parks, J. (1993). The contracts of individuals and organizations. Research in Organizational Behavior, $15,1-43$.

Sanitioso, R., Kunda, Z., \& Fong, G. T. (1990). Motivated recruitment of autobiographical memories. Journal of Personality and Social psychology, 59, 229-241.

Shanock, L. R., \& Eisenberger, R. (2006). When supervisors feel supported: Relationships with subordinates' perceived supervisor support, perceived organizational support, and performance. Journal of Applied Psychology, 91, 689-695.
Shen, H., Wan, F., \& Wyer, R. S., Jr. (2011). Cross-cultural differences in the refusal to accept a small gift: The differential influence of reciprocity norms on Asians and North Americans. Journal of Personality and Social Psychology, 100, 271-281.

Shore, L. M., \& Barksdale, K. (1998). Examining degree of balance and level of obligation in the employment relationship: A social exchange approach. Journal of Organizational Behavior: The International Journal of Industrial, Occupational and Organizational Psychology and Behavior, 19, 731-744.

Siemsen, E., Roth, A., \& Oliveira, P. (2010). Common method bias in regression models with linear, quadratic, and interaction effects. Organizational Research Methods, 13(3), 456-476.

Steenkamp, J. B. E., De Jong, M. G., \& Baumgartner, H. (2010). Socially desirable response tendencies in survey research. Journal of Marketing Research, 47, 199-214.

Thau, S., Derflerrozin, R., Pitesa, M., Mitchell, M. S., \& Pillutla, M. M. (2015). Unethical for the sake of the group: Risk of social exclusion and pro-group unethical behavior. Journal of Applied Psychology, 100, 98-113.

Tsui, A. S., Pearce, J. L., Porter, L. W., \& Tripoli, A. M. (1997). Alternative approaches to the employee-organization relationship: Does investment in employees pay off? Academy of Management Journal, 40, 1089-1121.

Turnley, W. H., Bolino, M. C., Lester, S. W., \& Bloodgood, J. M. (2003). The impact of psychological contract fulfillment on the performance of in-role and organizational citizenship behaviors. Journal of Management, 29, 187-206.

Umphress, E. E., \& Bingham, J. B. (2011). When employees do bad things for good reasons: Examining unethical pro-organizational behaviors. Organization Science, 22, 621-640.

Umphress, E. E., Bingham, J. B., \& Mitchell, M. S. (2010). Unethical behavior in the name of the company: The moderating effect of organizational identification and positive reciprocity beliefs on unethical pro-organizational behavior. Journal of Applied Psychology, 95, 769-780.

Umphress, E. E., Gardner, R. G., Stoverink, A. C., \& Leavitt, K. (2019). Feeling activated and acting unethically: The influence of activated mood on unethical behavior to benefit a teammate. Personnel Psychology., 73, 95-123.

Umphress, E. E., Ren, L. R., Bingham, J. B., \& Gogus, C. I. (2009). The influence of distributive justice on lying for and stealing from a supervisor. Journal of Business Ethics, 86, 507-518.

Wang, T., Long, L., Zhang, Y., \& He, W. (2019). A social exchange perspective of employee-organization relationships and employee unethical pro-organizational behavior: The moderating role of individual moral identity. Journal of Business Ethics, 159, 473-489.

Watkins, P., Scheer, J., Ovnicek, M., \& Kolts, R. (2006). The debt of gratitude: Dissociating gratitude and indebtedness. Cognition and Emotion, 20, 217-241.

Wayne, S. J., Shore, L. M., \& Liden, R. C. (1997). Perceived organizational support and leader-member exchange: A social exchange perspective. Academy of Management Journal, 40, 82-111.

Xiong, X., Guo, S., Gu, L., Huang, R., \& Zhou, X. (2018). Reciprocity anxiety: Individual differences in feeling discomfort in reciprocity situations. Journal of Economic Psychology, 67, 149-161.

$\mathrm{Xu}, \mathrm{T} .$, \& Lv, Z. (2018). HPWS and unethical pro-organizational behavior: A moderated mediation model. Journal of Managerial Psychology, 33, 265-278.

Zhang, S. (2020). Workplace spirituality and unethical pro-organizational behavior: The mediating effect of job satisfaction. Journal of Business Ethics, 161, 687-705.

Publisher's Note Springer Nature remains neutral with regard to jurisdictional claims in published maps and institutional affiliations. 